\title{
Economic Theory Has Nothing to Say about Policy (and Principles Textbooks Should Tell Students That)
}

\author{
David Colander \\ Middlebury College, Middlebury, Vermont 05753, USA
}

Eastern Economic Journal (2015) 41, 461-465. doi:10.1057/eej.2015.31; published online 25 May 2015

Let me start with a quiz:

- Question 1: According to economic theory, whenever possible government should avoid tariffs.

- Question 2: According to economic theory, the minimum wage lowers the welfare of society.

- Question 3: According to economic theory, if there are no externalities, the market is the preferable way of allocating resources.

The correct answer to each of these questions is false; economic theory, on its own, has nothing to say about policy. But, if you ask most economics majors, and many economists, the answer you would get to at least one of these questions would be true. That's sad, and suggests that there is a problem with how economic policy is taught.

Let me start with the reason why the answer to the three questions is false. Economic theory is deductive - it starts with a set of assumed premises, and through logic, develops implications of the premises. When done correctly, the conclusions of a theory say no more than the premises. Theory may reveal some hidden implications, but those implications are only reflective of the assumptions you put in.

Classical economists understood this distinction well, and to deal with it they carefully distinguished theorems from precepts. In their role as theorists, Classical economists explored the implications of a model's assumptions and developed theorems. A theorem is a conclusion that follows from an economic model; it ideally provides insights into the way the economy works, insights that are useful to think about policy issues, but the theorem itself is simply a statement of the implications of the assumptions of the model. Theorems have no direct implications for policy.

For Classical economists, a theorem was not debatable by serious economic scientists; given the assumptions, the conclusions followed. The Classical science of economics arrived at theorems that had no implications for policy. Nassau Senior, the first Classical economist to formally consider economic methodology, summarized Classical economist's view of the relationship between theory and policy when he wrote that economists' "conclusions, whatever be their generality and their truth, do not authorize him in adding a single syllable of (policy) advice."1 [Senior 1836] 
Classical economists recognized that society wanted more from economists than theories. Society wanted policy advice. They provided that policy advice not in the form of non-debatable theorems, but instead in the form of debatable precepts. A precept is a policy pronouncement that an economist thinks can be justified by reasoned argument. Precepts are based on the insights coming from models, combined with educated judgments about all relevant aspects of the decisions that the model assumes away for tractability reasons. These include moral judgments, historical knowledge, and institutional understanding. Precepts are the realm of economic statesmen, not economic scientists.

This additional knowledge needed to derive a policy precept means that policy oriented economists must be far more than economic theorists or scientists. They have to be moral philosophers, historians, sociologists, and humanists as well. J.M Keynes captured the many aspects of judgment that a good economic statesman would need to exhibit. He writes:

Good, or even competent, economists are the rarest of birds. An easy subject, at which very few excel! The paradox finds its explanation, perhaps, in that the master-economist must possess a rare *combination* of gifts. He must reach a high standard in several different directions and must combine talents not often found together. He must be mathematician, historian, statesman and philosopher - in some degree. He must understand symbols and speak in words. He must contemplate the particular in terms of the general, and touch abstract and concrete in the same flight of thought. He must study the present in the light of the past for the purposes of the future. No part of man's nature or his institutions must lie entirely outside his regard. He must be purposeful and disinterested in a simultaneous mood: as aloof and incorruptible as an artist, yet sometimes as near the earth as a politician.[Keynes 1925, p. 12]

\section{SHOULD ECONOMISTS TEACH PRECEPTS OR THEOREMS?}

My interest in this article is not with economics but with economic pedagogy: What blend of theorems and precepts should economists focus on in the principles of economics course. There is no one answer to that question, and, as long as professors make it clear whether they are teaching theorems or precepts, the course can be taught in various ways. Unfortunately, all too often theorems and precepts become blended, and students think they are learning non-debatable theorems when they are actually learning debatable precepts. The quiz questions that I started out this article with were posed as theorems, and as theorems, they had no implications for policy. Had they been presented as precepts, "true" answers would be possible, but only if all the qualifying nuances - the direct and implicit assumptions and ancillary judgments embedded in the model that led to the policy result - were taken into account in the question itself.

\section{The focus on precepts until the $1950 \mathrm{~s}$}

Looking at the history of economic pedagogy, we can see that teaching has shifted between the two. Up until the 1950s, the majority of principles textbooks in economics were designed to teach precepts. Solow nicely described the textbooks of the time as "civilized and discursive - sensible discussions of policy as seen by an economist." [Solow 1997] Because the texts were focused on teaching precepts, they were quite different from our principles books today. [See Colander 2005]. They had few graphs, and were mostly loose narratives about the relation of economic theory to policy. (Francis Edgeworth described Marshall's writings, which used that approach as the "zigzag windings of the flowery path of literature." [Edgeworth 1925, p. 288]) Exams reflected that nuanced vagueness. 
They were generally comprised of essay questions that had, in principle, many different answers; generally there was an expected answer but, ideally, what the examiners were looking for was an understanding of the nuance and an ability to reason from stated premises, not a specific answer.

Teaching nuanced precepts proved difficult to carry out in practice. The principles textbooks of the time tried, but they had mixed success. "High level" texts such as John Stuart Mill's or Alfred Marshall's, blended numerous qualifications into their discussion and did a reasonable job. They presented a few theorems, which they verbally qualified, and had sensible, but highly debatable, discussions of complex issues. On the basis of those books, it would be very hard for students to arrive at a definite policy conclusion based on economics alone.

The lesser known principles texts, which dominated the US principles market, were far less successful about blending theorems and precepts. Their discussions often turned into self-righteous moralizing. Consider, Francis Wayland's Principles, one of the leading US texts in the late mid 1800s. In discussing savings, he writes "It is obvious, upon the slightest reflection, that the Creator has subjected the accumulation of blessings of this life to some determinant laws. Every one, for instance, knows that no man can grow riche, without industry and frugality." [Wayland 1837 (1875)] Another leading US textbook in the early 1900s, Seligman [1905 (1929)] was a bit more successful. He writes "It is not competent to argue from internal free trade to international free trade" but that "in the main, then, the conclusion would seem to be that under certain conditions a protective policy is relatively defensible." How students were to interpret "in the main" and "relatively defensible" is unclear, and that ambiguity shows one of the problems with trying to teach precepts; the presentations of policy become either wishy washy, saying anything can result, or they convey the sense that students are expected to take the "master's" (i.e. the textbook author's) view on policy as definitive.

The difficulty of teaching primarily precepts in the principles texts was recognized, and there were attempts to avoid them. One of the earliest of these attempts was Pantelioni's [1898] Pure Economics, a principles book designed to teach theorems, not precepts. Pantelioni argued that precepts were too subjective to teach effectively, and that economists should concentrate on teaching beginning students what he called pure economics, which meant teaching students theorems that were not meant to be directly applied to policy. Pantelioni focused on teaching economic principles without the moralizing or the judgments inherent in precepts. His book was not widely adopted, and US principles books up until the 1950s primarily focused on teaching precepts.

\section{The samuelsonian textbook revolution}

The primary focus on precepts changed in the 1950s when Paul Samuelson's book (Samuelson, 1948) transformed the way principles of economic was taught. Instead of teaching precepts, Samuelson's book taught a blend of theorems and precepts that were tied together with the general equilibrium welfare economics that had developed in the 1930s. In presenting economic theory and policy this way he followed the economics profession, which had gravitated away from the Classical policy approach and had started directly relating theory to policy through a newly developed separate branch of economics - welfare economics. The hope was that welfare economics would allow economists to directly relate their theorems to policy, thereby eliminating the need to separate out theorems and precepts.

Unfortunately, the attempt failed, and welfare economics faded away as a separate field of economics. The reason it failed was that the attempt violated Hume's Dictum that you cannot derive a should from an is. Shoulds only follow from other shoulds. The initial 
economic welfare theory focused on Pareto Optimality and efficiency but it was quickly recognized that, without value judgments, it was impossible to move from theorems to policy.

To get around the problem formal welfare economics moved to a social welfare function (SWF) approach, in which economist's policy job was to apply society's social welfare function to their applied policy analysis. Given the appropriate SWF, it could theoretically integrate values into economist's policy analysis. The problem was that practically the social welfare function could not be implemented. A full specification of the Social Welfare Function required value decisions on a wide array of questions that went far beyond economics, and any tractable SWF was embedded with numerous implicit value decisions that eliminated any generality of the results. The SWF approach hid, but did not solve, the "values" problem. In addition, there was no way of unambiguously arriving at a social welfare function from individual utility functions without violating seemingly desirable aspects of the selection mechanism. [Arrow 1950] So, practically, the social welfare function approach quickly recognized was a dead end for practical policy. As early as 1957 Jan v. Graaff, in his famous study of welfare economics, recognize this, stating that "the possibility of building a useful and interesting theory of welfare economics - that is, one which consists of something more than the barren formalisms typified by the marginal equivalences of conventional theory — is exceedingly small." [v. Graaff 1957, p. 169]

By the 1970s, the impossibility of welfare economics avoiding the need to separate theorems and precepts was well understood by economic theorists, and as a result economists abandoned formal welfare economics as a practical guide to policy. Instead they used a variety of heuristics that embodied numerous, generally unstated, value judgments. Economists, such as Sen [1970] recognized the problem, and in their writings provided a deep understanding to the limitations and philosophical foundations of policy discussions. Unfortunately, that understanding did not make it into the standard principles texts, which continued to connect theory and policy in ways that cannot be justified except perhaps in the name of "pedagogical simplification." The result was the current situation — a situation in which theorems and precepts are often not distinguished in the texts, and principles students are often misled into thinking that economic theory leads to policy conclusions that it does not in fact lead to.

\section{CONCLUSION}

In my principles text I have struggled with how to best blend theorems and precepts. There is no easy solution. It is difficult to teach precepts objectively, and spelling out all the nuances required to move from theorems to precepts would turn the principles course into a philosophy course, not an economics course. But teaching only theorems would quickly lose the interest of most students. Students want relevance. So we are stuck with a blending of the two.

In determining what blend to use, I have two suggestions. The first is that we teach students that policy relevance does not come on the cheap. All students coming out of a principles course should know that before one can make a meaningful judgment about policy, there is a lot of history, moral philosophy, and additional peripheral knowledge that is needed to move from theory to policy. Even if we don't teach the nuance, we can teach the need for nuance in policy discussion. Every beginning economics student should know that economic theorems are not enough to arrive at policy conclusion.

My second suggestion is that we follow Classical economists and teach students the difference between theorems and precepts. It's a neat distinction that brings home to 
students the fact that policy relevance does not come on the cheap. Any principles students should know that: economic theory does not say that government should avoid tariffs; economic theory does not say that the minimum wage lowers the welfare of society; and economic theory does not say the market is good. These statements might all be true, but they do not follow directly from economic theory.

\section{Note}

1. Science can also involve bringing the theory to the data - empirically testing theories. But, given the undeveloped scientific empirical testing technology of the Classical period, they believed that establishing a formal empirical test of the theories was essentially impossible; the empirical statistical testing and computational technology was not up to it. This lack of formal empirical tests to validate a theory made them emphasize the limits of drawing policy implications of theory (Colander, 2011).

\section{References}

Arrow, Kenneth J. 1950. A Difficulty in the Concept of Social Welfare. The Journal of Political Economy, 58(4): 328-346.

Colander, David. 2005. What Economists Teach and What Economists Do. Journal of Economic Education, 36(3):Summer 249-260.

2011. Applied Policy, Welfare Economics, and Mill's Half Truths. in The Elgar Companion To Recent Economic Methodology. edited by John B. Davis, and D. Wade Hands. Cheltenham: Edward Elgar.

Edgeworth, Francis. 1925. Paper Relating to Political Economy. New York: Burt Franklin.

Keynes, J.M. 1925. Alfred Marshall, 1842-1924. in AC Pigou, Memorials of Alfred Marshall. London: Macmillan and Company, pp. 312-318.

Pantalioni, M. 1898. Pure Economics. translated by T. BostonBruce, New York: Kelly and Millman.

Samuelson, P. 1948 (1970). Economics, An Introductory Analysis, 8th ed. New York: McGraw-Hill.

Seligman, E. 1905 (1929). Principles of Political Economy, 12th ed. New York: Longmans, Green and Co. Sen, Amartya. 1970. The Impossibility of a Paratian Liberal. Journal of Political Economy, 78(1): 152-157.

Senior, Nassau William. [1836] 1951. An Outline of the Science of Political Economy. New York: Kelley.

Solow, Robert. 1997. How Did Economics Get that Way and What Way Did it Get? Daedalus, 126(1): $39-58$.

v. Graaff, J. 1957. Theoretical Welfare Economics. Cambridge: Cambridge University Press.

Wayland, F. 1837 (1875). The Elements of Political Economy, revised edition, New York: Leavitt, Lord \& Company. 